\title{
Genetic Differentiation in Response to Selection for Water-Soluble Carbohydrate Content in Perennial Ryegrass (Lolium perenne $\mathrm{L}$.)
}

\author{
J. A. Gallagher • L. B. Turner • A. J. Cairns • M. Farrell • \\ J. A. Lovatt • K. Skøt • I. P. Armstead • \\ M. O. Humphreys • I. Roldan-Ruiz
}

Published online: 10 July 2014

(C) The Author(s) 2014. This article is published with open access at Springerlink.com

\begin{abstract}
Plant carbohydrates are of increasing interest as renewable feedstocks to replace petrochemicals in the generation of fuels and production of high-value chemicals. Greater understanding of the genetic control of diversity in fructan synthesis and accumulation would facilitate more directed channelling of feedstock to process in a ryegrass biorefinery. Divergent populations produced by phenotypic selection for water-soluble carbohydrate content have been used to investigate relationships between traits, and to identify patterns of genetic differentiation which indicate genomic regions under high and low selection pressure. Selection for high watersoluble carbohydrate content was associated with increased synthesis of large fructan polymers and increased accumulation of above-ground plant biomass, particularly during spring. Three rounds of selection and two rounds of recombination resulted in widespread genetic differentiation across the whole genome, causing reduced allelic richness and increasing homozygosity at some loci. A smaller number of loci were shown to be subject to high selection pressure. Breeding material subjected to many years of selection for watersoluble carbohydrate also showed allelic differences which may reflect the consequences of high selection pressure at some of these same loci. However, some of the loci unaffected in the divergent selection experiment showed similar effects. This might arise from differences in linkage disequilibrium in these two sets of plant materials, but more likely from the
\end{abstract}

J. A. Gallagher $(\bowtie) \cdot$ L. B. Turner $\cdot$ A. J. Cairns $\cdot$ M. Farrell

J. A. Lovatt $\cdot$ K. Skøt $\cdot$ I. P. Armstead $\cdot$ M. O. Humphreys

Institute of Biological, Environmental and Rural Sciences,

Aberystwyth University, Gogerddan, Aberystwyth,

Ceredigion SY23 3EE, UK

e-mail: jbg@aber.ac.uk

I. Roldan-Ruiz

Growth and Development Group, Plant Sciences Unit, Institute for

Agricultural and Fisheries Research (ILVO), Melle, Belgium different genetic background of the germplasm. This illustrates the complex nature of the water-soluble carbohydrate trait in perennial ryegrass.

Keywords Allelic richness · Biorefining - Dry matter yield · Fructan polymers $\cdot$ SSR markers $\cdot$ Sugars

\begin{tabular}{|c|c|}
\hline \multicolumn{2}{|l|}{ Abbreviations } \\
\hline ANOVA & Analysis of variance \\
\hline C2 populations & $\begin{array}{l}\text { Second-generation selected populations } \\
\text { after two rounds of recombination }\left(\mathrm{C} 2^{\mathrm{s}} \text { witl }\right. \\
\text { random selection, } \mathrm{C} 2^{\mathrm{s}-} \text { with negative } \\
\text { selection for WSC content, } \mathrm{C} 2^{\mathrm{s}+} \text { with } \\
\text { positive selection for WSC content })\end{array}$ \\
\hline $\mathrm{CP}$ & Crude protein \\
\hline DM & Dry matter \\
\hline DP & Degree of polymerisation \\
\hline HPAEC-PAD & $\begin{array}{l}\text { High-performance anion-exchange } \\
\text { chromatography with pulsed } \\
\text { amperometric detection }\end{array}$ \\
\hline HPLC & High-performance liquid chromatography \\
\hline LTS & Lolium test set \\
\hline QTL & Quantitative trait locus/loci \\
\hline SNP & Single-nucleotide polymorphism \\
\hline SSR & Simple sequence repeat \\
\hline WSC & Water-soluble carbohydrate \\
\hline
\end{tabular}

\section{Introduction}

Plant carbohydrates are of increasing interest as renewable feedstocks to replace petrochemicals in the generation of fuels and production of high-value chemicals. In many temperate regions of the world, a large proportion of land area is occupied by grassland. Historically, this has been used 
for livestock production, and forage grasses, particularly ryegrasses, have been improved to provide increased nutritional value. One approach for achieving this has been by increasing water-soluble carbohydrate (WSC) content. Considerable genetic variation for WSC is available in perennial ryegrass and has been characterised to some extent [1]. It is this variation that has enabled the recurrent selection breeding programme at Aberystwyth to realise significant gain in WSC content over the past 30 or so years [2,3]. Consequently, high-sugar grasses offer the potential to produce high sugar yield for biorenewable applications without major change to the landscape.

Ryegrasses store their carbohydrate reserves in the form of polymers of fructose, water-soluble sugars called fructans, rather than as starch. Perennial ryegrass produces a diverse range of fructan molecules with different bond types $(\beta(2,1)$ and $\beta(2,6)$ ) which may be branched and/or linear and vary in length from 3-90 fructose units [4]. Potentially, this leads to the presence of a complex range of molecules available for conversion in a biorefinery. Different molecules may be particularly appropriate for specific applications. For example, some polymers may be suitable for the production of biosurfactants; carbohydrate surfactants are of interest because they are biodegradable and non-toxic to the environment $[5,6]$.

Greater understanding of the genetic control of diversity in fructan synthesis and accumulation would facilitate more directed channelling of feedstock to process. As part of the EU GRASP project (http://www.grasp-euv.dk/), trait-specific selections were carried out over two generations using populations derived from an initial set of 20 test genotypes (the Lolium test set (LTS)) in order to examine changes in allele frequencies associated with divergent selection as a means of validating single-nucleotide polymorphism (SNP) markers in candidate genes. One set of divergent populations was developed from test genotypes which included two members of the ryegrass WSC F2 mapping family in which WSC quantitative trait loci (QTL) have been characterised [1]. Significant changes in total WSC content were demonstrated in the GRASP divergent selections [7]. In addition, Farrar et al. [7] reported the possible co-selection of biomass accumulation during the experiment. Such straightforward co-selection would be extremely valuable if it could be demonstrated to be stable and consistent. The source of high WSC in this plant material came predominantly from the WSC mapping family LTS parents [8]; it would be expected mainly from Aurora. Aurora is a very early-heading cultivar and it might be that the biomass data published arise from early spring growth linked to flowering time [9]. The data of Farrar et al. [7] were for early spring only, and it is therefore unknown whether the positive effect observed on spring biomass accumulation is maintained over the growing season or whether a trade-off exists between spring growth and biomass accumulation later in the growth season. Comparison of the high WSC and low WSC selections revealed differences in allele frequency for only one of the six candidate genes studied (soluble acid invertase 1:4). Simple sequence repeat (SSR) markers were included in this GRASP experiment as putative neutral markers. However, SSRs linked to QTL regions will not necessarily prove to be neutral. For a complex trait, like WSC content, under multi-locus control, significant numbers of SSRs may be located next to QTL regions and would show selection effects. Indeed, Turner et al. [8] showed preliminary evidence of such effects and, in fact, selection effects on these markers may provide further insight into the genetic control of the trait being studied.

These divergent populations from the GRASP project provide excellent material for further study of the genetic control and physiology of the high-sugar trait. The aims of the work described here were threefold: first, to examine the coselection of traits (sugar/fructan content and biomass production) in the GRASP experiment in more detail to confirm the associations of these traits; second, to extend the set of SSR markers to cover more of the genome and to study patterns of genetic differentiation in the second-generation populations (after two rounds of recombination (C2)) to confirm the widespread nature of the selection effects; and third, to examine certain genomic regions (identified by the GRASP experiment as being under high and low selection pressure during selection for WSC content) in early- and advanced-generation high-sugar ryegrass cultivars to investigate the generality of their role in the genetic control of WSC content.

\section{Materials and Methods}

\section{Plant Material}

The structure of the GRASP selection experiment, along with basic maintenance and characterisation of plant material in the glasshouse, was previously described by Farrar et al. [7]. Briefly, a synthetic $\mathrm{C} 0$ of 600 plants was first created by pair-crossing four plants (LTS01, LTS05, LTS09 and LTS18) with contrasting WSC phenotypes from the GRASP LTS of 20 plants. The 3-year mean total WSC content (by anthrone colour reaction) of samples taken from potted plants of these founder plants in the glasshouse during spring and autumn ranged from 16.4 to $22.3 \%$ dry matter (DM). The range was 16.9 to $25.9 \% \mathrm{DM}$ in 2007 , the year samples were taken from the C2-selected populations in the GRASP selection experiment. Further information on these four LTS founder plants was reported by Posselt et al. [10]. The C0 population was randomly divided into two. One half underwent three rounds of divergent selection for WSC content at a selection pressure of $10 \%$ and two rounds of recombination whilst the other half was subject to random selection under the same conditions. 
The phenotypic scores used for selection were from anthrone measurements of total WSC content of all herbage above a cut at a stubble height of approximately $4 \mathrm{~cm}$. This above-ground biomass was predominantly leaf but included some sheath/ tiller base material. For each generation, these procedures produced full populations of 300 unique individual plants $\left(\mathrm{C}, \mathrm{C}^{-}\right.$and $\left.\mathrm{C}^{+}\right)$from which selected populations of 30 plants $\left(\mathrm{C}^{\mathrm{s}}, \mathrm{C}^{\mathrm{s}^{-}}\right.$and $\left.\mathrm{C}^{\mathrm{s}+}\right)$ were identified for polycrossing to produce the following generation. The populations analysed here are those from the second generation and all members of the populations are genetically unique individual plants. They have been renewed each year from a sub-set of a few tillers and are currently still maintained in $130-\mathrm{cm}$ pots in a frost-free glasshouse.

Additionally, two ryegrass cultivars were grown for genetic analysis. Pre-basic seed of AberElan (not actively selected for WSC) and AberMagic (a recent high-sugar grass cultivar selected for WSC and yield) was sown in March 2011 in an unheated, unlit glasshouse. Fresh young leaf material was sampled in August 2011 from 96 individual plants of each cultivar for DNA extraction and marker analysis. Mean herbage WSC content of the same plants was measured in the

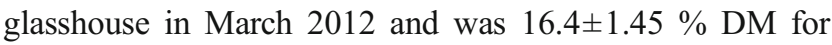
AberElan and 22.1 $\pm 2.26 \%$ DM for AberMagic.

\section{Field Experiments}

Tillers were removed from the $900 \mathrm{C} 2$ generation plants $(300$ $\mathrm{C} 2$ random, $300 \mathrm{C}^{-}$negative and $300 \mathrm{C}^{+}$positive populations) soon after germination in August 2006 (the year the seed was produced) and used to establish a field trial of spaced plants for assessing heading date the following spring. This trial was close to the institute on an open site close to sea level and exposed to westerly winds. The soil was a well-drained, permeable, medium loam. Single copies of each individual plant were planted out in October 2006. The plants were randomised within, but not between populations. Rows of 10 plants at a spacing of $30 \mathrm{~cm}$ were surrounded by a border row of the cultivar Parcour. Fertiliser (60 kg/ha N:P:K, $5: 24: 24)$ and a spray to control broad-leaved weeds were applied in March 2007. Heading date was scored on individual plants as the first date, in days after April 1, when three heads had emerged from the flag leaf. No variation in heading date was noticed in the border plants, suggesting few positional effects occurred within the scale of the spaced plant field trial.

Also, in August 2006, and as part of a larger trial of various test populations and controls, small $2-\mathrm{m}^{2}$ plots of the three C2 populations were sown with further seed from the original stocks. The conditions at the field site were the same as for the spaced plant trial. A seed rate of $3 \mathrm{~g} / \mathrm{m}^{2}$ was used in a fully randomised design with four blocks. The plots were cut back and broad-leaved weeds controlled with a single spray at the end of September 2006. Before the winter, a further cut was carried out in October 2006. The plots received $100 \mathrm{~kg} / \mathrm{ha}$ nitrogen in the sowing year. In all subsequent years (2007, 2008, 2009), they received $400 \mathrm{~kg} /$ ha nitrogen divided into eight applications; two in early spring and one after each cut. The plots were harvested for analysis at 5-6-week intervals from April to October in 2007, 2008 and 2009 with a Haldrup plot harvester set at a cutting height of approximately $6 \mathrm{~cm}$. The fresh weight of the full sample was measured in the field. A sub-sample of between 300 and $400 \mathrm{~g}$ fresh matter was dried overnight in an oven set at $80^{\circ} \mathrm{C}$ and $\mathrm{DM}$ yield calculated from DM percentage of the sub-sample. In year 1, around half of the dry sample was milled to pass through a 2-mm screen, and this was further sub-sampled for chemical analysis of nutritional value by near infra-red spectroscopy (NIR), calibrated against a suitable validation set. Crude protein (CP) was calculated from nitrogen content with a multiplication factor of 6.25 . The yields of the individual harvests were summed to give annual yields.

\section{Glasshouse Experiments}

Some of the samples from the experiment previously described by Farrar et al. [7] were used for part of this study. Briefly, single copies of the $900 \mathrm{C} 2$ generation plants (300 C2 random, $300 \mathrm{C} 2^{-}$negative and $300 \mathrm{C}^{+}$positive populations) were grown in $90-\mathrm{cm}$ pots, stood 24 to a flat tray, in a frost-free glasshouse. The individual plants were randomised within but not between the populations. The 30 selected $\mathrm{C}^{\mathrm{s}^{-}}$and $\mathrm{C}^{\mathrm{s}^{+}}$ came from across the full populations so it is unlikely that any significant positional effects on phenotype occurred. Extracts were produced by Farrar et al. [7] in March 2007 and assayed for the total WSC content of each individual plant from the C2 full populations of 300 plants. Here, the extracts from the three selected populations of 30 plants were further analysed by high-performance liquid chromatography (HPLC) to identify the different sugars present. Sugars were separated and quantified by isocratic HPLC on a Dionex (Camberley, UK) instrument comprising an ASI-100 automated sample injector, P580 pump and Chromeleon instrument interface, on a $300 \times$ 7.8-mm column of Aminex HPX87-C (Bio-Rad, Hemel Hempstead, UK) at $85{ }^{\circ} \mathrm{C}$, protected by an in-line $0.5-\mu \mathrm{m}$ filter and a Carbo- $\mathrm{C}$ guard column. The mobile phase was degassed water at a flow rate of $0.6 \mathrm{ml} / \mathrm{min}$. This column completely resolved fructan molecules with a degree of polymerisation (DP) of 3 from other fructan polymers. Short-chain fructan molecules with a DP of 4-6 have been distinguished as shoulders or pronounced tails on the main fructan peak and integrated separately from long-chain polymers. In this communication, DP3, DP4 and DP5-6 have been described as oligofructans and DP $>6$ as polymeric fructan. Sugars were detected by refractive index (Shodex RI-71 refractive index monitor) and quantified against authentic standards. All 
polymeric fructans were quantified against chicory inulin (Sigma). The relative distribution of polymers of different chain lengths was assessed by high-performance anion exchange chromatography with pulsed amperometric detection (HPAEC-PAD). Aliquots of $25 \mu \mathrm{l}$ were injected onto a Carbopac PA100 (Dionex: $4 \times 250 \mathrm{~mm}$ ) column at $30{ }^{\circ} \mathrm{C}$ and eluted with $1.0 \mathrm{ml} / \mathrm{min} 100 \mathrm{mM}$ sodium hydroxide and a discontinuous linear gradient from 0 to $1.0 \mathrm{M}$ sodium acetate. Sugars were detected by pulsed amperometry using an ED40 electrochemical detector.

$\mathrm{DM}$ production of the individually selected $\mathrm{C} 2$ plants in pots, over the full growing season, was determined in the glasshouse broadly as described previously [7], but with seven cuts taken between early March and late October 2009. Single copies of the $\mathrm{C} 2^{\mathrm{s}}, \mathrm{C}^{\mathrm{s}-}$ and $\mathrm{C} 2^{\mathrm{s}+}$ plants were grown in $130-\mathrm{cm}$ pots in a different glasshouse and in different layouts both within and between populations compared with the 2007 experiment. They were again randomised within but not between populations to avoid potential confounding effects from mixing smaller, slower growing $\mathrm{C}^{\mathrm{S}^{-}}$plants with larger, faster growing $\mathrm{C}^{\mathrm{s}+}$ plants in the context of a glasshouse growth experiment. If the $\mathrm{C}^{\mathrm{s}-}$ plants were shaded and growth was artificially reduced early in the growing season, there would be knock-on effects throughout the experiment. This would artificially accentuate any difference between the populations. The presence of a confounding positional effect cannot therefore be excluded, but the populations were arranged in a small part (approximately $12 \%$ growing area) of a large glasshouse to impose minimal variation in temperature and irradiance. Harvests were taken on March 2, April 15, May 20, July 7, August 3, September 14 and October 26. On each date, all top growth above a cutting height of about $4 \mathrm{~cm}$ was removed from the plants with hand shears, placed in labelled paper bags and oven-dried to constant mass at $80{ }^{\circ} \mathrm{C}$ without any separation of different tissue types.

\section{Statistical Analysis}

Statistical analysis of the field sward data was carried out with the standard menu-driven procedures included in GenStat ${ }^{\circledR}$ for Windows ${ }^{\circledR}$, version 13.2 [11]. Analysis of variance (ANOVA) was carried out with plot values. Both two-way ANOVA with population and year as fixed effects and block as a random effect, and one-way ANOVA of individual years were used for the DM data, WSC yield and CP yield data as appropriate. Outputs presented include predicted means, $F$ test probabilities ( $P$ values) and least significant differences (LSD) at the appropriate level.

Experiments on individual plants (the glasshouse experiments and spaced plant field trial) were carried out on single copies of the individual plants and so no statistical analyses have been performed. Population means are presented to illustrate general trends.

\section{Genetic Analysis}

An experimental set of SSRs was identified with the aim of characterising a framework of markers which were codominant, reliable, easily scorable in diverse material and located every $20-25 \mathrm{cM}$ on each chromosome. This marker set was mapped on to the ryegrass WSC F2 mapping family linkage map with JoinMap ${ }^{\circledR}$, and marker positions are shown in Fig. 1. Markers with the prefix ' $r v$ ' are fromViaLactia Biosciences (see Gill et al. [12]) and used under licence. Extraction of DNA was described by Farrar et al. [7]. SSR markers were run on an $\mathrm{ABI}$ capillary sequencer as described by Turner et al. [1].

For the estimation of genetic diversity and differentiation parameters, a set of five populations was considered. These were the four 'LTS' plants, the 30 selected ' $\mathrm{C} 0$ ' plants, the 30 selected ' $\mathrm{C} 2$ 's' plants, the 30 selected ' $\mathrm{C} 2^{\mathrm{s}-}$ ' plants and the 30 selected ' $\mathrm{C} 2^{\mathrm{s}+}$, plants. Allelic richness per population and $\mathrm{F}_{\mathrm{ST}}$ values between pairs of populations were computed using the software package FSTAT 2.9.3.2 [13]. GENEPOP 4.2 [14, 15] was used to estimate observed $\left(\mathrm{H}_{\mathrm{O}}\right)$ and expected $\left(\mathrm{H}_{\mathrm{E}}\right)$ heterozygosities, inbreeding coefficients $\left(\mathrm{F}_{\mathrm{IS}}\right)$, and allelic and genotype diversity per locus and per population. The allelic differentiation between pairs of populations per locus and the LD between pairs of loci in each population were also estimated with GENEPOP. Regions of the genome under significant selection pressure were identified using the infinite island model [16] implemented in LOSITAN [17]. Markers that showed $\mathrm{F}_{\mathrm{ST}}$ higher than $95 \%$ of neutral distribution were inferred to be subject to divergent selection, and markers that showed $\mathrm{F}_{\mathrm{ST}}$ lower than $95 \%$ of neutral distribution were inferred to be subject to balancing selection.

\section{Results}

Phenotypic Traits

The content of individual soluble sugars in relation to total WSC content is shown in Fig. 2a. The $\mathrm{C}^{\mathrm{s}-}$ population had, numerically, the lowest WSC content but a high proportion of WSC as sucrose and fructose. In relative terms, the $\mathrm{C}_{2}^{\mathrm{s}+}$ population had the lowest amounts of sucrose and fructose, but much higher fructan content. The $\mathrm{C} 2^{\mathrm{s}+}$ population also had the highest proportion of fructan as large polymers of DP $>6$ (Fig. 2b). The size of the polymers in the fructan pool can be further assessed by qualitative analysis on HPAEC-PAD. Extracts from one $\mathrm{C}^{\mathrm{s}^{-}}$and one $\mathrm{C}^{\mathrm{s}+}$ plant were measured (Fig. 3). The chromatography traces were similar up to 13min retention time (equivalent to a DP of between 6 and 10; unpublished data), although the detector response indicated slightly higher concentrations in the $\mathrm{C}^{\mathrm{s}+}$ plant. After this, the 


\section{CHROMOSOME}
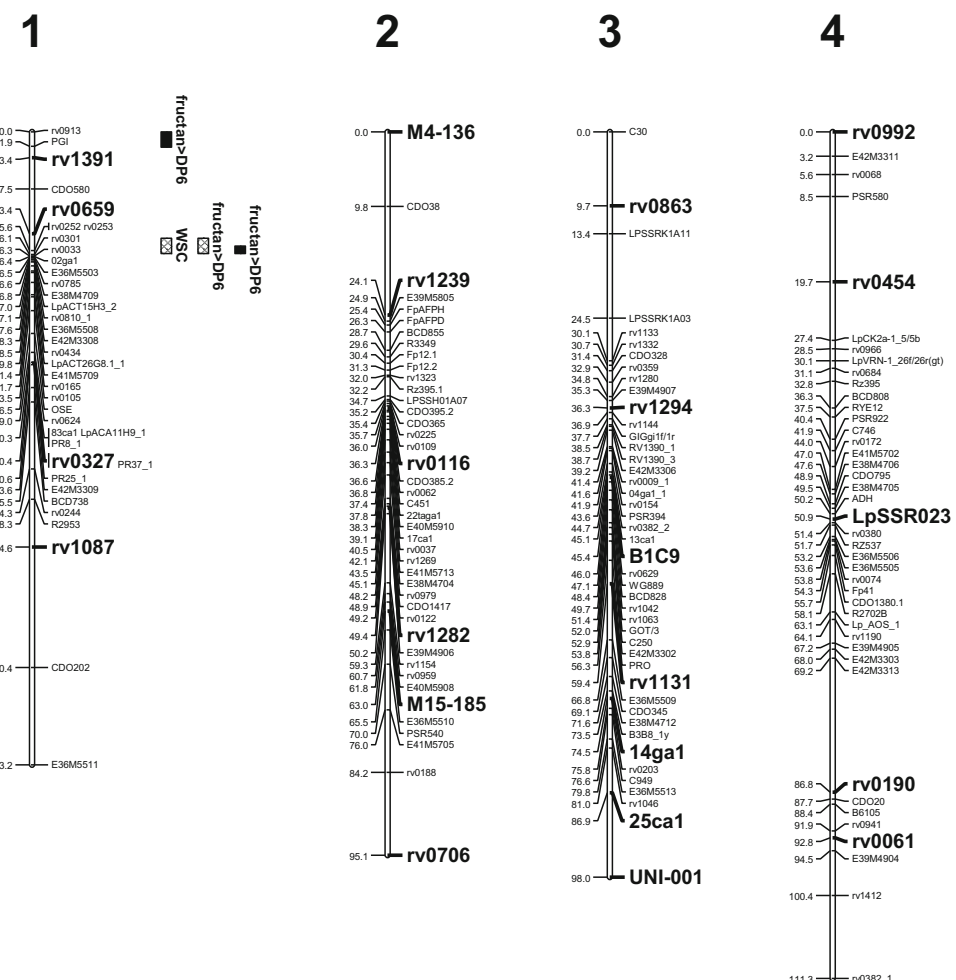

5

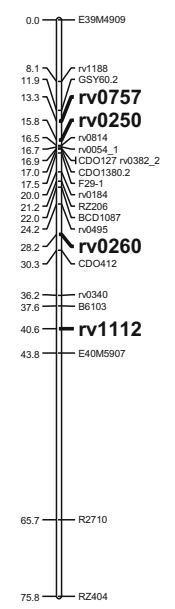

6

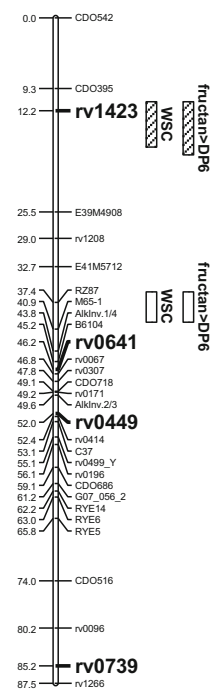

7

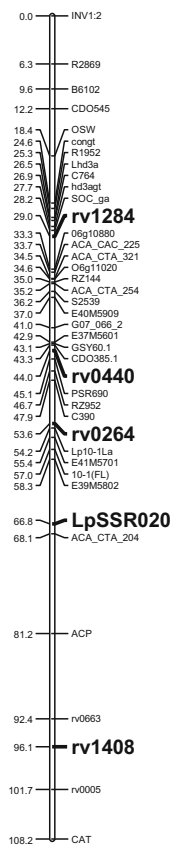

Fig. 1 Linkage map of the WSC F2 mapping family showing the positions of markers in the SSR set used for association studies, and QTL for total WSC and polymeric fructan content. Chromosome designations conform to the Triticeae numbering. Markers included in the analysis are indicated in larger, bold font. Fructan and WSC QTL data are from Turner et al. (2006); QTL bars represent the 1 - LOD fall interval from MQM mapping. Open bars are leaf QTL in the spring, hatched bars are leaf QTL in the autumn, cross-hatched bars are tiller base QTL in the spring and filled bars are tiller base QTL in the autumn. Total WSC, WSC; polymeric fructan, fructan $>D P 6$ traces were substantially different. The $\mathrm{C} 2^{\mathrm{s}^{-}}$plant contained virtually no large polymeric fructan whereas the $\mathrm{C}^{\mathrm{s}+}$ contained considerable quantities of large polymers which had not completely eluted by the time the column cleanup cycle began after 42 min run time.

The DM yield of the 90 selected plants from the C2 generation was measured in the glasshouse by seven cuts over the growing season(Fig. 4). In general, the $\mathrm{C}_{2}{ }^{\mathrm{s}+}$ population had, numerically, higher DM yield than the $\mathrm{C}^{2}{ }^{\mathrm{s}-}$, and particularly so for the first three cuts. Overall, this resulted in a trend for higher annual dry matter yield for $\mathrm{C}^{\mathrm{s}+}(26.6 \pm 1.4 \mathrm{~g})$ than for $\mathrm{C}^{\mathrm{S}^{-}}(22.2 \pm 0.8 \mathrm{~g})$. The $\mathrm{C} 2^{+}$population also had higher annual dry matter yield than the $\mathrm{C}^{-}$in the field (Table 1). There was a significant $(P<0.001)$ effect of year but no population by year interaction over the course of the field experiment. The $\mathrm{C}^{+}$and $\mathrm{C} 2{ }^{-}$populations were significantly $(P<0.5)$ different from each other, although not always from the unselected $\mathrm{C} 2$ population, in all 3 years. The overall year means were all significantly $(P<0.05)$ different from each other. The yield advantage of the $\mathrm{C}^{+}$population was present throughout more of the year in the field, but particularly early and late in the growing season. However, all the GRASP populations were lower yielding than commercial reference cultivars.

Nutritional value was only measured (by NIR) in year 1, but significant differences between the $\mathrm{C}^{+}$and $\mathrm{C} 2{ }^{-}$populations in WSC content $(P<0.05)$ in the expected direction were observed at all except the first harvest date. WSC content was highest in July in all three GRASP C2 populations. The $\mathrm{C}^{+}$ population was $18 \%$ higher than the $\mathrm{C} 2{ }^{-}$in May $(244.5 \mathrm{mg} / \mathrm{g}$ DM WSC and $206.5 \mathrm{mg} / \mathrm{g}$ WSC respectively) and $20 \%$ higher in July (286.6 and $239.6 \mathrm{mg} / \mathrm{g}$ ). Over the course of the growing season, carbohydrate yield was significantly higher $(P<0.001)$ in the $\mathrm{C}^{+}$population than in the $\mathrm{C}^{-}$ population (Table 1). CP content was lower $(P<0.05)$ in the $\mathrm{C} 2^{+}$population on all dates except the fourth harvest in August. It was lowest in May in all three GRASP C2 populations; the $\mathrm{C2}^{+}$was $15 \%$ lower than the $\mathrm{C}^{-}$at this harvest (92.5 mg/g DM CP and $108.1 \mathrm{mg} / \mathrm{g}$ CP respectively). However, over the growing season, the higher DM yield of the $\mathrm{C}^{+}$ was sufficient to result in higher CP yield from this population (Table 1).

Heading dates for the full C2 populations of 300 plants in the field in year 1 were 42.8 days for the $\mathrm{C} 2$, with the other 
Fig. 2 Soluble sugar content, analysed by HPLC, of all top growth removed by cutting to a 4-cm stubble height for plants of the three $\mathrm{C} 2$ selected GRASP populations in pots in the glasshouse in early March. Data are based on single copies of the individual plants and so no statistical analyses have been performed. The population means $(n=30)$ are presented to illustrate trends. a Sugar content as milligrams/gram DM; fructan (horizontally/vertically crosshatched blocks), sucrose (vertically-hatched blocks), glucose (solid blocks) and fructose (open blocks). The full height of the blocks represents total WSC. b Components of the fructan pool as a percentage of total fructan content (polymeric fructan $>$ DP6, cross-hatched blocks; DP5-6 fructan, hatched blocks; DP4 fructan, solid blocks; and DP3 fructan, open blocks)
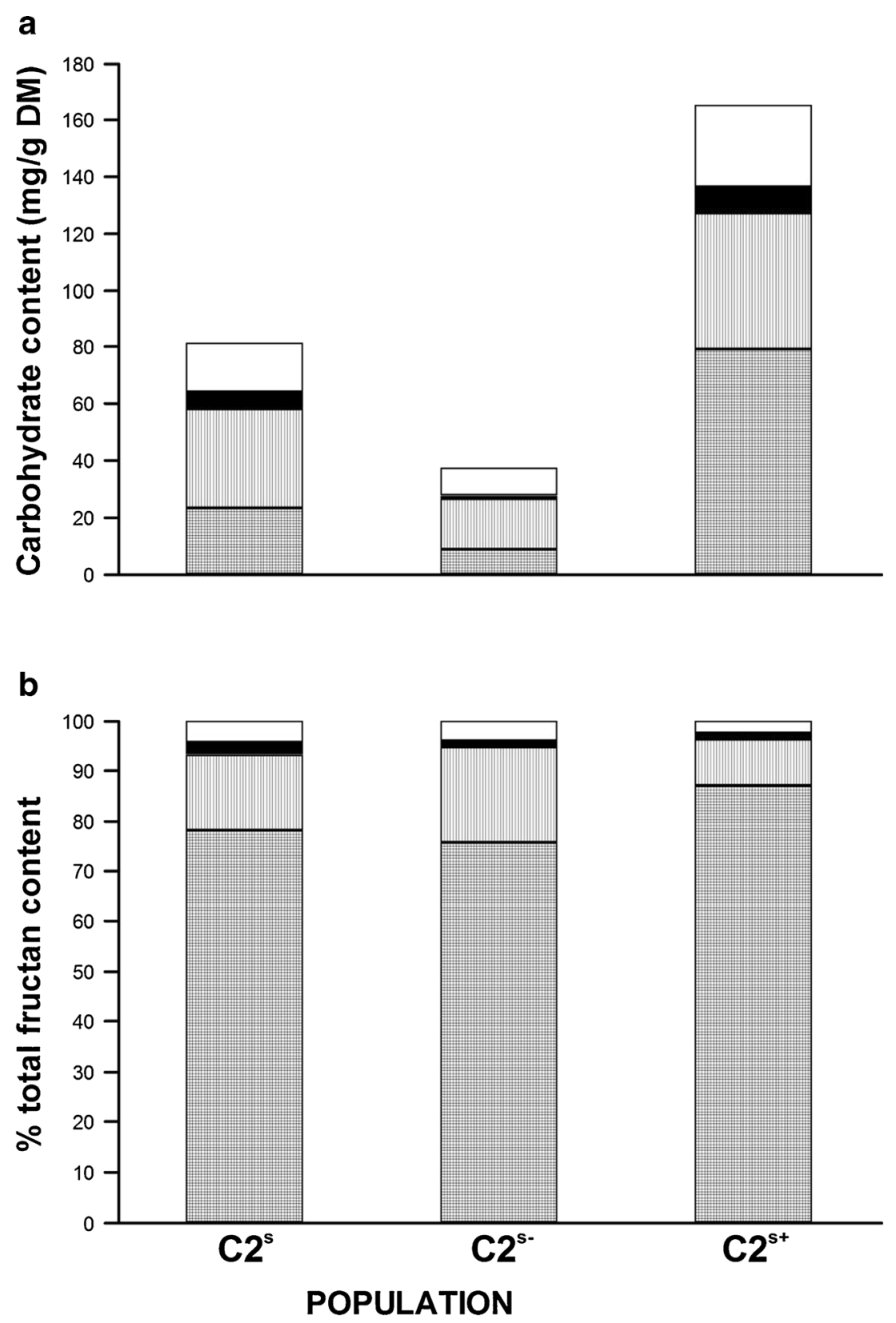

two populations slightly later at 43.0 days for both the $\mathrm{C} 2^{-}$and the $\mathrm{C} 2^{+}$. The heading dates for the 30 plants selected from the full populations of 300 plants were 43.6 days for the $\mathrm{C} 2{ }^{\mathrm{s}}$, 42.4 days for the $\mathrm{C} 22^{\mathrm{s}^{-}}$and 38.8 days for the $\mathrm{C} 2^{\mathrm{s}+}$ respectively. This field trial was carried out with single copies of each of the individual members of the populations and so no statistical analyses have been performed.

\section{Genetic Differentiation}

The marker set chosen for this study proved reliable and robust. Only two markers (rv0260 on chromosome 5 and rv0706 on chromosome 2) were out of Hardy-Weinberg equilibrium in all populations (data not shown). Observed heterozygosity was slightly lower than expected heterozygosity in all populations, indicating either the occurrence of null alleles or a slight level of inbreeding (Table 2). Allelic richness decreased in the $\mathrm{C}^{\mathrm{s}+}$ population. $\mathrm{F}_{\mathrm{ST}}$ values demonstrated that clear differentiation of the $\mathrm{C} 2$ populations had occurred during the course of the selection experiment. The non-selected population was not different from the $\mathrm{C} 0$ population. The positive and negative populations were significantly different from each other, and both were different from the non-selected population and the C0.

Significant $P$ values for linkage disequilibrium were detected between many pairs of marker loci within chromosomes, and also between pairs of marker loci on different chromosomes (Table 3 ). In the $\mathrm{C} 0$ generation, there were more marker 


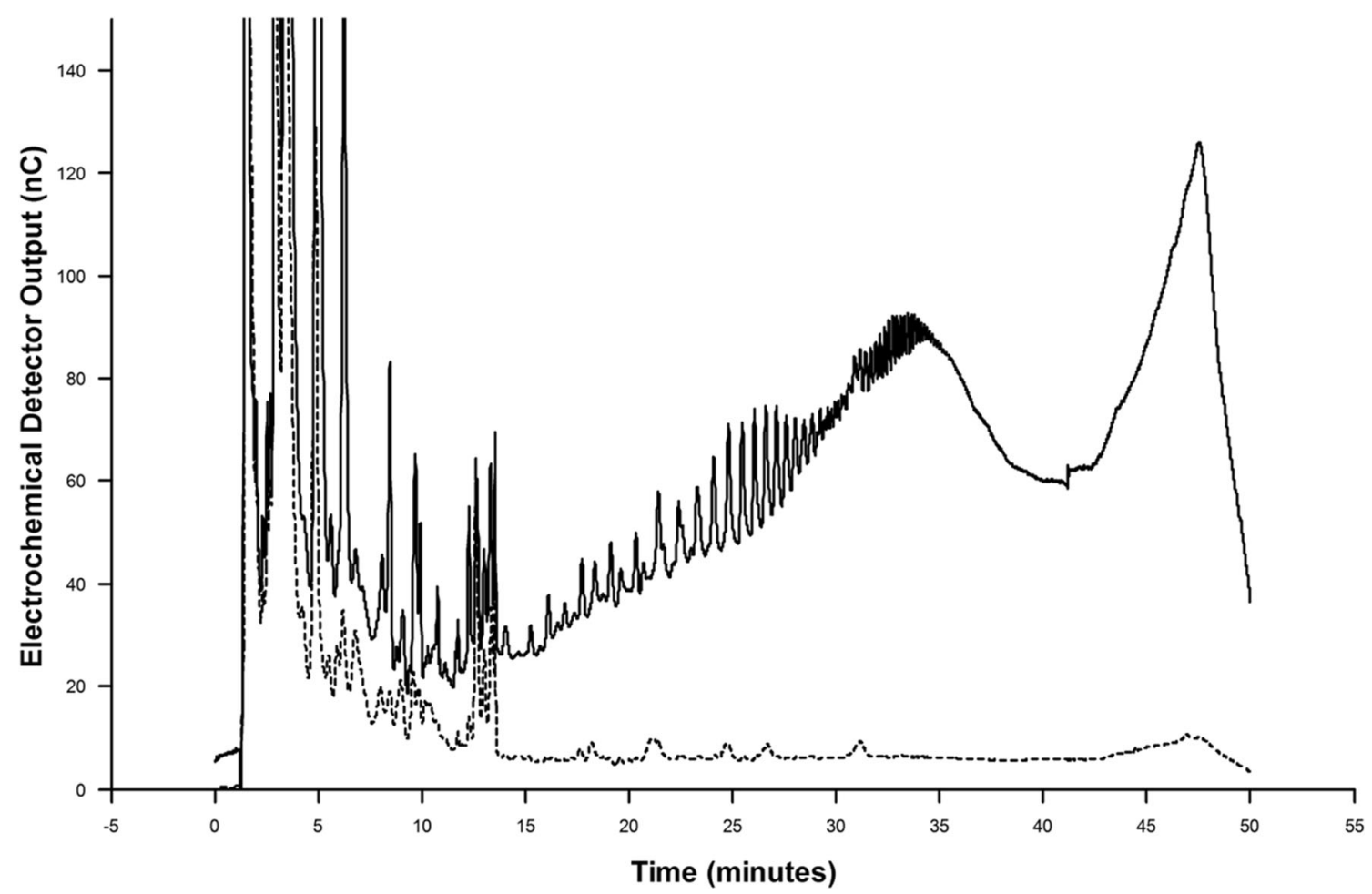

Fig. 3 Chromatograms showing the different length fructan polymers in the WSC pool from two representative plants with contrasting WSC content. $\mathrm{C}^{\mathrm{s}^{-}}$(fine/dashed line) and $\mathrm{C}^{\mathrm{s}^{+}}$(heavy line) analysed at the same sugar concentration, but back calculated to a dry matter basis for presentation

loci pairs in disequilibrium within chromosomes than across different chromosomes. The decay of linkage disequilibrium over generations led to a decrease in the number of marker pairs in disequilibrium by the $\mathrm{C} 2$ generation and in particular a $50 \%$ reduction in the number of pairs in disequilibrium within chromosomes. The $\mathrm{C} 2{ }^{\mathrm{S}}$ and $\mathrm{C}^{\mathrm{s}-}$ populations had similar numbers of marker loci pairs in linkage disequilibrium. These were predominantly within chromosomes and adjacent analysed markers or marker pairs with one intervening marker. The more distant pair in the $\mathrm{C} 2{ }^{\mathrm{s}}$ population was on chromosome 2 (M15185 and rv0116, $26.69 \mathrm{cM}$ apart). A greater number of marker loci pairs in linkage disequilibrium were found in the $\mathrm{C}^{\mathrm{s}+}$ population, and in contrast, $61 \%$ of these were associations across different chromosomes (Tables 3 and 4). These relationships across chromosomes covered all seven chromosomes, although chromosome 5 was involved in fewest marker pairs (Table 4). Several marker loci, particularly on chromosomes 1,2 , and 6 , are located in or close to QTL regions (Table 4).

There was little evidence that any significant genetic drift at the allelic level occurred during the experiment as there were few examples of significant divergence between the $\mathrm{C} 2^{\mathrm{s}}$ and
Fig. 4 DM yield (g) of plants of the $\mathrm{C} 2$ generation maintained in the glasshouse over the growing season. Data are based on single copies of the individual plants. No statistical analyses have been performed and the population means are presented to illustrate trends. Mean DM of the three selected GRASP populations from material removed by cutting each plant to a stubble height of $4 \mathrm{~cm}: \mathrm{C}^{\mathrm{s}}$ (triangle), $\mathrm{C} 2^{\mathrm{s}}$ (square), $\mathrm{C} 2^{\mathrm{s}^{+}}$(circle). $n=30$

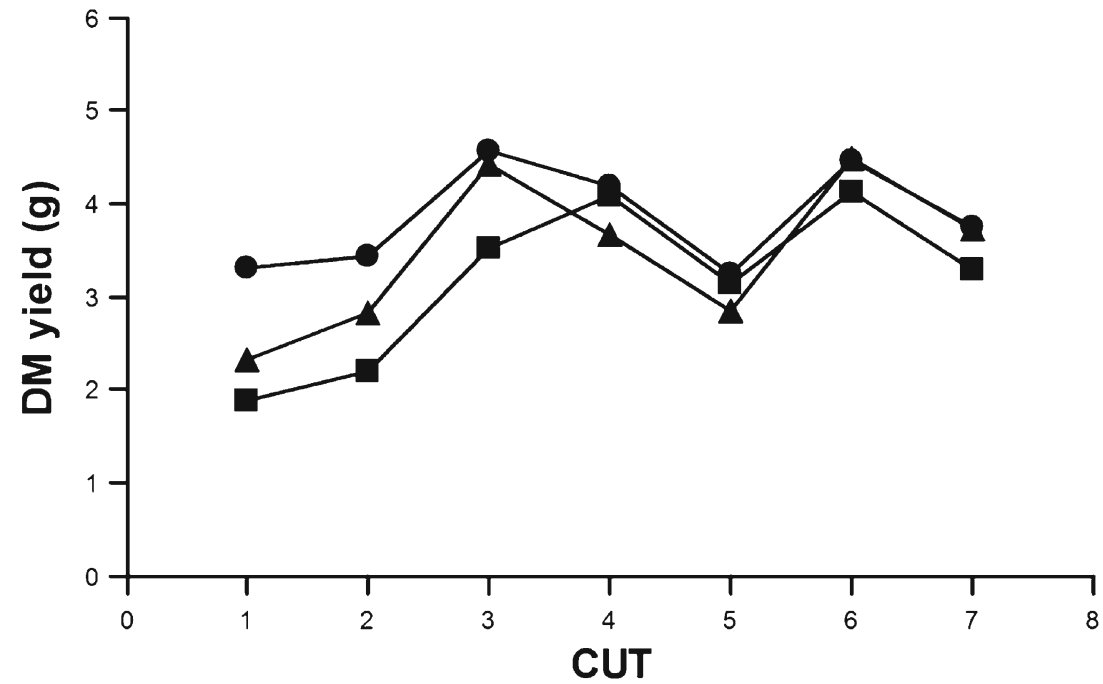


Table 1 Annual dry matter yield and nutritional quality for the C2 GRASP populations in field plots

\begin{tabular}{|c|c|c|c|c|c|c|c|c|}
\hline \multirow[b]{2}{*}{ Year } & & \multicolumn{3}{|c|}{ GRASP population } & \multirow[t]{2}{*}{$P$} & \multirow[t]{2}{*}{ LSD $5 \%$} & \multicolumn{2}{|c|}{ Reference cultivar } \\
\hline & & $\mathrm{C} 2$ & $\mathrm{C} 2^{-}$ & $\mathrm{C} 2^{+}$ & & & AberMagic & Premium \\
\hline \multicolumn{9}{|c|}{ Annual dry matter yield (t/ha) } \\
\hline 1 & 2007 & 12.24 & 10.78 & 12.70 & 0.011 & 1.075 & 18.33 & 15.79 \\
\hline 2 & 2008 & 11.38 & 9.96 & 12.00 & 0.010 & 1.087 & 15.62 & 14.10 \\
\hline 3 & 2009 & 12.32 & 11.77 & 13.26 & 0.009 & 0.759 & 16.80 & 15.34 \\
\hline Mean & & 11.98 & 10.84 & 12.65 & $<0.001$ & 0.502 & 16.92 & 15.08 \\
\hline \multicolumn{9}{|c|}{ Annual water-soluble carbohydrate yield (kg/ha) } \\
\hline 1 & 2007 & 468.0 & 375.5 & 505.5 & $<0.001$ & 47.0 & 892.5 & 641.5 \\
\hline \multicolumn{9}{|c|}{ Annual crude protein yield (kg/ha) } \\
\hline 1 & 2007 & 271.9 & 243.8 & 262.5 & 0.014 & 18.4 & 340.6 & 293.8 \\
\hline
\end{tabular}

DM yield (t/ha) of forage from small field plots over 3 years. WSC and CP yield for year $1(\mathrm{~kg} / \mathrm{ha})$. Data were summed over six cuts between April and October and analysed as individual years by one-way ANOVA. $n=4$. Significance levels are indicated and LSD is the least significant difference for comparing population means at $P<0.05$. Data for AberMagic and Premium from the same trial are presented as reference cultivars but have been excluded from the statistical analysis

C0 populations (Table 5). However, highly significant allelic differentiation between the positive and negative populations was observed across all seven chromosomes, for 30 out of the 35 SSRs studied. In many, but not all, instances, the divergence between the positive and random selections was more significant than between the negative and random selections. This allelic differentiation led to a similar pattern of genotypic differentiation (data not shown). LOSITAN software was used to identify which loci from this large set of markers with significant allelic differentiation showed significant divergent selection (Table 5). This suggested that markers on chromosomes 2 and 6 were subject to significant selection pressure in

Table 2 Population differentiation

\begin{tabular}{|c|c|c|c|c|c|}
\hline & & \multicolumn{4}{|c|}{ Population } \\
\hline & & $\mathrm{C} 0$ & $\mathrm{C} 2^{\mathrm{s}}$ & $\mathrm{C} 2^{\mathrm{s}^{-}}$ & $\mathrm{C} 2^{\mathrm{s}+}$ \\
\hline \multicolumn{2}{|l|}{ Number of individuals } & 30 & 30 & 30 & 30 \\
\hline \multicolumn{2}{|l|}{ Allelic richness } & 2.956 & 2.894 & 2.839 & 2.434 \\
\hline \multicolumn{2}{|l|}{$\begin{array}{l}\text { Expected heterozygosity } \\
\left(\mathrm{H}_{\mathrm{E}}\right)\end{array}$} & 0.667 & 0.658 & 0.641 & 0.528 \\
\hline \multicolumn{2}{|l|}{$\begin{array}{l}\text { Observed heterozygosity } \\
\qquad\left(\mathrm{H}_{\mathrm{O}}\right)\end{array}$} & 0.552 & 0.498 & 0.552 & 0.466 \\
\hline \multicolumn{2}{|l|}{$\mathrm{F}_{\mathrm{IS}}$} & 0.172 & 0.243 & 0.138 & 0.117 \\
\hline \multirow[t]{4}{*}{$\mathrm{F}_{\mathrm{ST}}$} & $\mathrm{C} 0$ & 0 & 0.0082 & $0.0656^{* *}$ & $0.0627 * *$ \\
\hline & $\mathrm{C} 2^{\mathrm{s}}$ & & 0 & $0.0493 * *$ & $0.1073 * *$ \\
\hline & $\mathrm{C} 2^{\mathrm{s}-}$ & & & 0 & $0.1922 *$ \\
\hline & $\mathrm{C} 2^{\mathrm{s}+}$ & & & & 0 \\
\hline
\end{tabular}

Description of the initial $\mathrm{C} 0$ generation and the three selected populations from the $\mathrm{C} 2$ generation. Allelic richness (A) from FSTAT, and expected heterozygosity, observed heterozygosity and $\mathrm{F}_{\mathrm{IS}}$ from GENEPOP. $\mathrm{F}_{\mathrm{ST}}$ values for population pairs (FSTAT) with significance levels are indicated $(* * P<0.01)$ the $\mathrm{C} 2^{\mathrm{s+}}$ population and markers on chromosomes 1,2 and 6 in the $\mathrm{C}^{\mathrm{S}-}$ population. Marker 14gal on chromosome 3 also showed a significant selection effect.

\section{Genetic Diversity at Selected Loci}

Eleven contrasting loci were selected, from the $\mathrm{C} 2$ population allelic differentiation and LOSITAN results in Table 5, to examine allelic richness and homozygosity in the GRASP populations and in two ryegrass cultivars (AberElan and AberMagic) from the Aberystwyth breeding programme. The four markers with low differentiation and no significant selection effect were on chromosomes 3, 4, 5 and 7 (Table 6). The seven markers with the most significant allelic differentiation, negligible genetic drift and (except for rv1391) significant selection effects were located on chromosomes 1, 2, 3 and 6. The most common allele in the initial plant material (the LTS plants) was present in the WSC F2 mapping family for all these eleven marker loci. Within the GRASP selection experiment, in general, the non-selected markers had a lower number of alleles and showed no loss of alleles by the $\mathrm{C} 2$ generation and few changes in the frequency of the most common allele. There were only small differences between the three $\mathrm{C} 2^{\mathrm{S}}$ populations. The level of homozygosity was relatively high but little affected by selection. In contrast, the SSRs showing selection effects had a higher number of alleles, although comparison of allele number with degree of allelic differentiation for the full marker set showed only a low, although significant, correlation $(r=0.386 ; P=0.035)$. Within the GRASP selection experiment, the markers showing significant differentiation by the $\mathrm{C} 2$ generation accumulated particular alleles (all of WSC F2 mapping family origin and not necessarily the most common allele from the earlier generations) in the $\mathrm{C}^{\mathrm{s}+}$ population. This led 
Table 3 Summary of linkage disequilibrium in the $\mathrm{C} 0$ and $\mathrm{C} 2$ selected populations

\begin{tabular}{|c|c|c|c|c|c|}
\hline \multicolumn{2}{|c|}{ Marker pairs in linkage disequilibrium } & \multicolumn{4}{|c|}{ Population } \\
\hline & & $\mathrm{C} 0$ & $\mathrm{C} 2^{\mathrm{s}}$ & $\mathrm{C} 2^{\mathrm{s}-}$ & $\mathrm{C} 2^{\mathrm{s}+}$ \\
\hline \multirow{5}{*}{$\begin{array}{l}\text { Total marker pairs Within } \\
\text { a chromosome }\end{array}$} & & 37 & 25 & 22 & 31 \\
\hline & total & 28 & 14 & 15 & 12 \\
\hline & with the next analysed marker & 16 & 11 & 9 & 9 \\
\hline & with the next but one analysed marker & 9 & 2 & 4 & 2 \\
\hline & more distant & 3 & 1 & 2 & 1 \\
\hline On different chromosomes & & 9 & 11 & 7 & 19 \\
\hline
\end{tabular}

to a higher homozygosity for these loci in the positive selection compared with the negative and random selections. In some cases, this was accompanied by the complete loss of alleles: for example M4-136 alleles 185 and 200 were not found in the $\mathrm{C} 2{ }^{\mathrm{s}+}$ population.

Table 4 Location of marker pairs in linkage disequilibrium across chromosomes for the $\mathrm{C}^{\mathrm{s}^{-}}$and $\mathrm{C}^{\mathrm{s}^{+}}$selected populations

\begin{tabular}{|c|c|c|c|c|}
\hline \multirow[t]{2}{*}{ Population } & \multicolumn{2}{|l|}{ Locus 1} & \multicolumn{2}{|l|}{ Locus 2} \\
\hline & Marker 1 & Chromosome & Marker 2 & Chromosome \\
\hline \multirow[t]{7}{*}{$\mathrm{C} 2^{\mathrm{s}-}$} & rv1391 ${ }^{a}$ & 1 & SSR020 & 7 \\
\hline & $\operatorname{rv} 0659^{a}$ & 1 & B1C9 & 3 \\
\hline & $\mathrm{rv} 0659^{\mathrm{a}}$ & 1 & $\mathrm{rv} 0641^{\mathrm{a}}$ & 6 \\
\hline & $\operatorname{rv} 0116^{\mathrm{a}}$ & 2 & rv1284 & 7 \\
\hline & M15185 & 2 & rv1284 & 7 \\
\hline & UNI-001 & 3 & $\operatorname{rv} 0449^{a}$ & 6 \\
\hline & rv0190 & 4 & SSR020 & 7 \\
\hline \multirow[t]{19}{*}{$\mathrm{C} 2^{\mathrm{s}+}$} & rv0327 & 1 & rv0641 ${ }^{\mathrm{a}}$ & 6 \\
\hline & rv0327 & 1 & rv0449 & 6 \\
\hline & rv1087 & 1 & rv1239 ${ }^{a}$ & 2 \\
\hline & rv1087 & 1 & $\operatorname{rv} 0116^{\mathrm{a}}$ & 2 \\
\hline & rv1087 & 1 & rv0706 & 2 \\
\hline & rv1087 & 1 & rv0863 & 3 \\
\hline & rv $1239^{a}$ & 2 & rv0992 & 4 \\
\hline & rv0116 & 2 & UNI-001 & 3 \\
\hline & 14ga1 & 3 & rv1284 & 7 \\
\hline & $25 \mathrm{ca} 1$ & 3 & rv1408 & 7 \\
\hline & UNI-001 & 3 & rv0641 ${ }^{\mathrm{a}}$ & 6 \\
\hline & UNI-001 & 3 & rv0449 & 6 \\
\hline & UNI-001 & 3 & rv1408 & 7 \\
\hline & rv0992 & 4 & $\mathrm{rv} 0250^{\mathrm{a}}$ & 5 \\
\hline & rv0190 & 4 & $\mathrm{rv} 0250^{\mathrm{a}}$ & 5 \\
\hline & rv0190 & 4 & $\mathrm{rv} 1423^{\mathrm{a}}$ & 6 \\
\hline & rv0190 & 4 & rv0641 & 6 \\
\hline & rv0992 & 4 & rv1284 & 7 \\
\hline & rv0449 & 6 & rv1408 & 7 \\
\hline
\end{tabular}

${ }^{\text {a }}$ Loci located in or close to QTL regions (from Turner et al. (2006))
Allele number was lower in AberMagic than in AberElan for 5 of the 11 markers studied (Table 6). Four of these were markers showing selection effects in the GRASP experiment. This was combined with increases in the frequency of homozygous genotypes for the most common allele for these markers. However, in regard to homozygosity, the difference between markers from the SIG and NOT SIG groups from the GRASP experiment was less clear, and homozygosity was higher in AberMagic for most of the markers examined. The most extreme example of allele loss and increased homozygosity in AberMagic was for rv1391 on chromosome 1.

\section{Discussion}

Farrar et al. [7] have already described the positive selection of the $\mathrm{C}^{2+}$ population with high sugar content from the low baseline in the $\mathrm{C} 0$ generation. The difference between the $\mathrm{C}^{\mathrm{s}+}$ and $\mathrm{C} 2^{\mathrm{s}}$ populations was greater than between the $\mathrm{C} 2^{\mathrm{s}-}$ and $\mathrm{C} 2^{\mathrm{s}}$ populations, suggesting that the 'positive' selection was more intense than the 'negative' selection. The data presented here to examine the component sugars of the total WSC pool in these plants are from single copies of the individual plants and for just the last generation at the end of the selection experiment, but comparable results have been observed for the previous $\mathrm{C} 1$ generation. Calculation of total WSC content for the three $\mathrm{C}^{\mathrm{s}}$ populations from HPLC data by summing the individual named peaks showed trends that repeat the effects from the previous analyses [7], except for a relative underestimation of the WSC content of the $\mathrm{C}^{\mathrm{s}}{ }^{\mathrm{s}}$ population. This might have arisen from the accumulation of sugars which were unidentified peaks on the HPLC traces or of sugars that are not detected by a refractive index monitor. Within the identified sugar peaks, the main effect appeared to be an increase in the proportion of WSC present as high molecular weight polymeric fructan in the $\mathrm{C}^{\mathrm{s}+}$ selection. Therefore, at a molecular level, the selection may have been achieved through changes in polymeric fructan metabolism. This would minimise the osmotic consequences of storing high concentrations of sugar. This study has suggested that, 
Table 5 Marker differentiation between pairs of populations from the $\mathrm{C} 2$ generation

\begin{tabular}{|c|c|c|c|c|c|c|c|c|c|}
\hline \multirow{2}{*}{ Marker } & & \multicolumn{2}{|c|}{$\mathrm{C} 2^{\mathrm{s}+} / \mathrm{C} 2^{\mathrm{s}^{-}}$} & \multicolumn{2}{|l|}{$\mathrm{C} 2^{\mathrm{s}+} / \mathrm{C} 2^{\mathrm{s}}$} & \multicolumn{2}{|l|}{$\mathrm{C} 2^{\mathrm{s}-} / \mathrm{C} 2^{\mathrm{s}}$} & \multicolumn{2}{|l|}{$\mathrm{C} 2^{\mathrm{s}} / \mathrm{C} 0$} \\
\hline & & $P$ & $\mathrm{~F}_{\mathrm{ST}}$ & $P$ & $\mathrm{~F}_{\mathrm{ST}}$ & $P$ & $\mathrm{~F}_{\mathrm{ST}}$ & $P$ & $\mathrm{~F}_{\mathrm{ST}}$ \\
\hline rv1391 & 1 & 0.00000 & 0.347696 & 0.00897 & 0.083971 & 0.00073 & 0.115391 & 0.50268 & -0.00654 \\
\hline rv0659 & 1 & 0.00000 & 0.158655 & 0.23035 & -0.00361 & 0.00261 & 0.110816 & 0.66133 & -0.01331 \\
\hline rv0327 & 1 & 0.00000 & 0.190718 & 0.00000 & 0.087636 & 0.00000 & $\mathbf{0 . 1 5 7 5 4 8}(0.999)$ & 0.61292 & -0.00588 \\
\hline rv1087 & 1 & 0.00000 & 0.218757 & 0.57712 & 0.005336 & 0.00000 & $\mathbf{0 . 2 0 0 5 5 2}(1.000)$ & 0.04502 & 0.020236 \\
\hline M4136 & 2 & 0.00000 & $\mathbf{0 . 3 1 2 3 5 9}(0.977)$ & 0.00000 & 0.161017 & 0.00297 & 0.054642 & 0.67420 & 0.001478 \\
\hline rv1239 & 2 & 0.00000 & $\mathbf{0 . 3 6 0 4 8 9}(0.975)$ & 0.00000 & $\mathbf{0 . 2 5 7 8 5 3}(0.994)$ & 0.30653 & -0.00067 & 0.04290 & 0.037254 \\
\hline rv0116 & 2 & 0.00000 & $\mathbf{0 . 3 5 3 8 3 9}(0.996)$ & 0.00000 & $\mathbf{0 . 1 8 4 3 6 5}(0.983)$ & 0.00250 & 0.075329 & 0.02988 & 0.046916 \\
\hline rv1282 & 2 & 0.00000 & $\mathbf{0 . 5 3 1 4 4 4}(0.999)$ & 0.00006 & 0.240937 & 0.00188 & $\mathbf{0 . 1 4 4 4 8 5}(0.985)$ & 0.02647 & 0.069186 \\
\hline M15185 & 2 & 0.00000 & $\mathbf{0 . 3 7 0 9 1 3}(0.985)$ & 0.00000 & $\mathbf{0 . 2 8 0 6 2}(0.994)$ & 0.00121 & 0.060059 & 0.01079 & 0.058434 \\
\hline rv0706 & 2 & 0.00000 & 0.187992 & 0.00283 & 0.104483 & 0.00609 & 0.061885 & 0.06863 & 0.010002 \\
\hline rv0863 & 3 & 0.00000 & 0.256943 & 0.00000 & 0.132814 & 0.00002 & 0.061133 & 0.05345 & 0.015053 \\
\hline rv1294 & 3 & 0.00000 & 0.193139 & 0.02958 & 0.049254 & 0.05210 & 0.037699 & 0.35081 & 0.000585 \\
\hline B1C9 & 3 & 0.00020 & 0.079867 & 0.00287 & 0.05082 & 0.49755 & -0.00624 & 0.34797 & 0.017258 \\
\hline rv1131 & 3 & 0.31981 & -0.00267 & 0.19864 & 0.004312 & 0.96775 & -0.01601 & 0.12981 & 0.027514 \\
\hline 14gal & 3 & 0.00000 & 0.267126 & 0.00000 & $\mathbf{0 . 2 3 1 0 0 3}(0.998)$ & 0.48220 & -0.01242 & 0.56421 & 0.004349 \\
\hline $25 \mathrm{ca} 1$ & 3 & 0.00030 & 0.092065 & 0.00647 & 0.058148 & 0.36553 & 0.00013 & 0.44469 & -0.00351 \\
\hline UNI-001 & 3 & 0.00000 & 0.118323 & 0.00006 & 0.09051 & 0.03222 & 0.001246 & 0.19623 & 0.010563 \\
\hline rv0992 & 4 & 0.00004 & 0.123302 & 0.00000 & 0.097078 & 0.01252 & 0.038794 & 0.32395 & 0.00829 \\
\hline rv0454 & 4 & 0.00017 & 0.077622 & 0.00196 & 0.050224 & 0.17449 & 0.016122 & 0.38211 & -0.00339 \\
\hline SSR023 & 4 & 0.00000 & 0.116066 & 0.00000 & 0.121297 & 0.07896 & 0.006157 & 0.36884 & -0.00534 \\
\hline rv0190 & 4 & 0.00000 & 0.26608 & 0.00077 & 0.131379 & 0.00995 & 0.021937 & 0.70876 & -0.00709 \\
\hline rv0061 & 4 & 0.67280 & -0.01308 & 0.07876 & 0.041943 & 0.24718 & 0.014377 & 0.84807 & -0.01693 \\
\hline rv0757 & 5 & 0.00000 & 0.040856 & 0.00050 & 0.042359 & 0.00029 & -0.01641 & 0.58134 & 0.003156 \\
\hline rv0250 & 5 & 0.01613 & 0.186876 & 0.01177 & 0.055929 & 1.00000 & 0.042822 & 0.53819 & -0.00581 \\
\hline rv0260 & 5 & 0.04379 & 0.028602 & 0.01914 & 0.036401 & 0.00029 & 0.07516 & 0.40317 & -0.00115 \\
\hline rv1112 & 5 & 0.00022 & 0.068498 & 0.04209 & 0.079685 & 0.00000 & 0.112738 & 0.07291 & 0.022513 \\
\hline rv1423 & 6 & 0.00000 & $\mathbf{0 . 4 6 5 5 2 2}(0.999)$ & 0.00000 & $\mathbf{0 . 3 6 2 9 1 3}(0.999)$ & 0.00012 & 0.056105 & 0.00585 & 0.035114 \\
\hline rv0641 & 6 & 0.00000 & 0.233325 & 0.00696 & 0.071427 & 0.00409 & 0.052481 & 0.21925 & 0.003053 \\
\hline rv0449 & 6 & 0.00000 & 0.291457 & 0.01017 & 0.039972 & 0.00000 & $\mathbf{0 . 1 3 2 8 1 1}(0.991)$ & 0.72664 & -0.01038 \\
\hline rv0739 & 6 & 0.00000 & 0.139397 & 0.00000 & $\mathbf{0 . 2 2 7 8 3 3}(0.985)$ & 0.00027 & 0.07516 & 0.66580 & -0.00971 \\
\hline rv1284 & 7 & 0.00097 & 0.086796 & 0.00255 & 0.051365 & 0.07950 & 0.026573 & 0.23903 & 0.006912 \\
\hline rv0440 & 7 & 0.00273 & 0.045173 & 0.46900 & -0.00262 & 0.00891 & 0.047494 & 0.04435 & 0.0321 \\
\hline rv0264 & 7 & 0.00000 & 0.18113 & 0.00478 & 0.054113 & 0.00162 & 0.072771 & 0.16568 & 0.011362 \\
\hline SSR020 & 7 & 0.00398 & 0.083861 & 0.00139 & 0.11579 & 0.05466 & 0.021833 & 0.01770 & 0.041197 \\
\hline rv1408 & 7 & 0.06105 & 0.002364 & 0.25538 & -0.00913 & 0.80120 & $-\underline{0.0153(0)}$ & 0.21895 & 0.001715 \\
\hline
\end{tabular}

$P$ values are for allelic differentiation between selected populations $(n=30)$ from GENEPOP output. $\mathrm{F}_{\mathrm{ST}}$ values are from LOSITAN. Markers identified as being under divergent selection by LOSITAN are highlighted (bold type) and the $P$ value corresponding to $P$ (Simul $\mathrm{F}_{\mathrm{ST}}<$ sample $\mathrm{F}_{\mathrm{ST}}$ ) is given in parentheses. Markers identified as being under balancing selection by LOSITAN are highlighted (italic type and underlined) and the $P$ value corresponding to $P\left(\right.$ Simul $\mathrm{F}_{\mathrm{ST}}<$ sample $\left.\mathrm{F}_{\mathrm{ST}}\right)$ is given in parentheses. Markers are arranged in the order they occur on the linkage map

when appropriate variation is present in the source population, phenotypic expression of high WSC may be associated with increased fructan content.

The selection for high WSC was only accompanied by a likely increase in biomass yield during the early part of the growing season, although DM production was numerically higher in the $\mathrm{C}^{\mathrm{s}+}$ on all harvest dates. Overall, this early growth was sufficient to increase annual DM yield, as there did not appear to be any comparable increase in yield of the other populations later in the growing season. The DM data were for single copies of the individual plants in the glasshouse for just 1 year, and the possibility of positional effects cannot be completely eliminated. However, the trends in both this DM yield data and the WSC data discussed above are 
Bioenerg. Res. (2015) 8:77-90

87

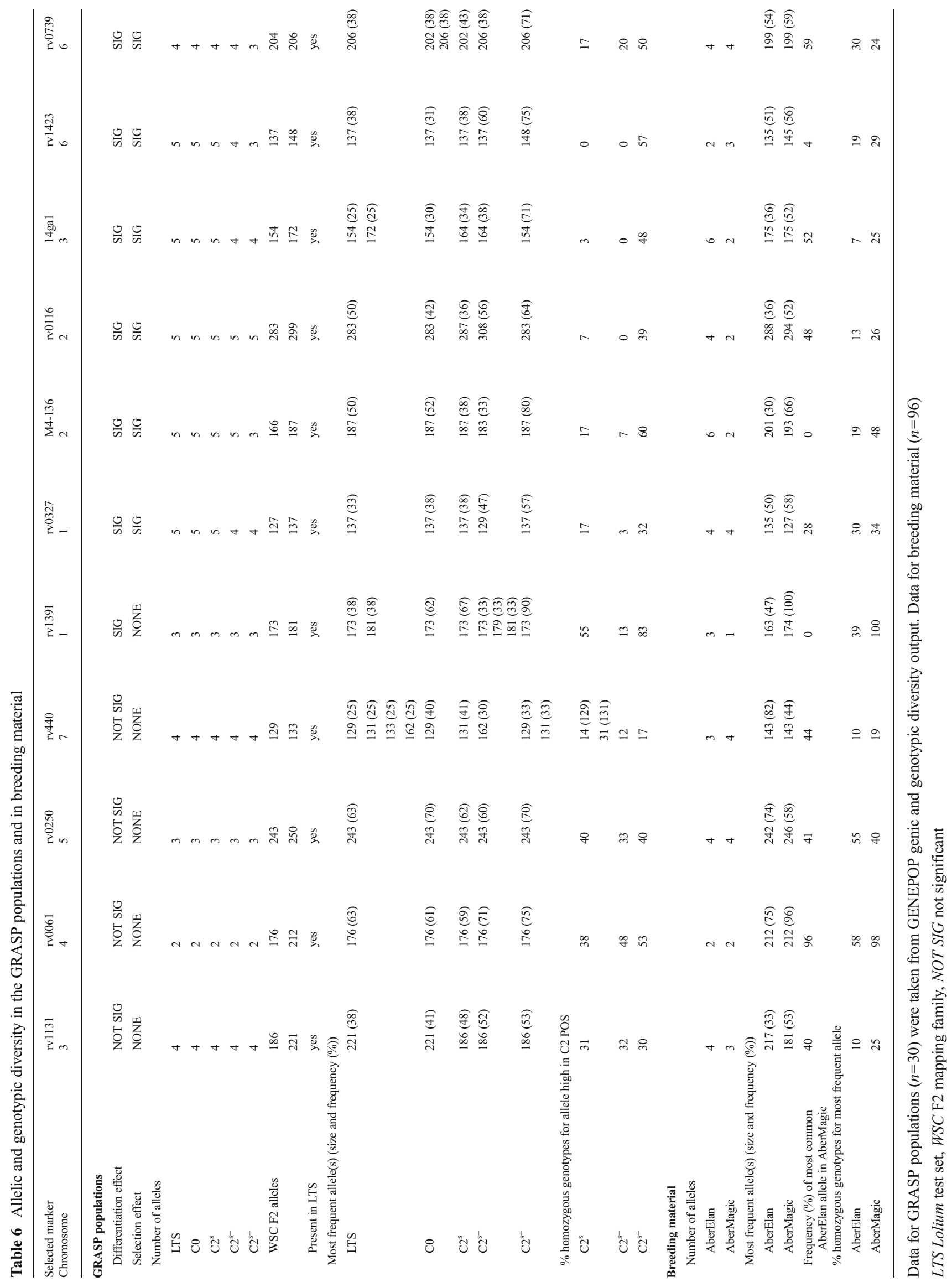

Springer 
strongly supported by the data from the mini-swards in the field over 3 years. Early spring growth can be associated with early flowering, but there was no indication of major changes in heading date in the second-generation GRASP populations. The yield differences may not have been dramatic, but they do demonstrate the important point that high WSC accumulation does not necessarily draw carbon supply away from growth processes which would conflict with yield. Overall, this may explain why it has been possible to successfully select for both yield and high sugar during ryegrass breeding programmes at IBERS, Aberystwyth, without introducing any unwanted changes in heading date.

The current SSR studies with this plant material have provided information on the genetic basis of the phenotypic response. Other workers have also demonstrated that SSR markers can be less neutral than might be expected during selection experiments. In wheat, long-term improvement (from 1845 to 2004) of a range of quality and productivity traits resulted in significant allelic changes in nearly half the SSRs tested [18]. In maize, there were changes in the allele frequencies of SSRs during selection; some markers were flanking known QTL but others were spread across the genome [19]. These widespread unexplained effects may be a reflection of the number of unknown, small QTL with cumulative effects that exist for many quantitative traits. In the current work, allelic differentiation within the SSR set was observed on all chromosomes. WSC content is a quantitative trait with expected multi-locus control. Nevertheless, these results could indicate multiple control loci on individual chromosomes or confounding effects due to carry over by linkage during the small number of rounds of recombination during the experiment. However, in general, limited (at best perhaps $1 \mathrm{~kb}$ ) linkage disequilibrium would be expected in outbreeding species like the forage grasses [20], and linkage disequilibrium decay has been shown to be rapid in other studies with ryegrass $[21,22]$. During the current experiment, linkage disequilibrium within a chromosome approximately halved between the $\mathrm{C} 0$ and $\mathrm{C} 2$ generations, with the decreases larger as the distance between markers increased. At the same time, linkage disequilibrium between markers on different chromosomes increased substantially in the positive selection, reinforcing the suggestion that this population was subject to high selection pressure and that at least some of the shifts detected here were brought about by selecting for high WSC.

Nine of the 35 SSRs used in this study are on chromosome regions that have previously been shown to be linked to WSC or fructan QTL [1]. Five of these nine markers showed a significant LOSITAN selection effect, but so did six markers not previously associated with QTL in our work. QTL markers were no more likely to show strong allelic differentiation across all population comparisons within the $\mathrm{C} 2$ generation than non-QTL markers (9.1\% compared with $11.5 \%$ ). However, all QTL markers except rv0250 on chromosome 5 showed a strong allelic differentiation in the $\mathrm{C}^{\mathrm{s}^{+}} / \mathrm{C}^{\mathrm{s}-}$ comparison, although so did 14 out of the 26 other markers. Eighteen of the 26 marker loci pairs in disequilibrium across chromosomes in $\mathrm{C}^{\mathrm{s}+}$ and $\mathrm{C}^{\mathrm{s}-}$ included one marker in a QTL region, although only one pair involved two markers in QTL regions. Together, these results confirm the importance of the QTL segregating in the IBERS WSC F2 mapping population in regulating WSC content, and also indicate the probable existence of other, as yet unknown, QTL for WSC present in the ryegrass genome. The LOSITAN analysis suggests that some of these QTL may be located on chromosomes 1 and 3. Chromosome 3 would seem to be a likely candidate for a major QTL as WSC QTL have been reported on chromosomes 3 and 7 in perennial ryegrass [23], but the current data do not accurately define the position of this putative QTL. Further work is needed to characterise these new QTL more fully and identify the possibility of underlying candidate genes of fructan metabolism. No association with genes of fructan metabolism has been demonstrated for the WSC/fructan QTL previously reported for perennial ryegrass [1].

Changes in allele frequencies during selection are commonly associated with decreases in allelic richness [18]. Loss of alleles, along with increases in the homozygosity of the remaining alleles, was observed in the GRASP selection experiment for most of the markers showing a significant LOSITAN selection effect. These changes were greatest in the $\mathrm{C}^{\mathrm{S}+}$ population, providing further supporting evidence for a stronger positive selection than negative selection. The number of alleles was lower in AberMagic than in AberElan for three of the six 'selection' markers, but only one of these was a QTL marker in the WSC F2 mapping family. Additionally, one of four non-selected markers showed reduced allelic richness. The most extreme example of low allele richness and high homozygosity in AberMagic was for rv1391. This has been mapped near the isozyme PGI at the top of chromosome 1 , which is associated with WSC and fructan QTL [1]. If reduced allelic richness is used as evidence for a region of the genome under selection pressure during cultivar production, then, overall, this suggests that while there may be some common elements to the genetic control of WSC in the plant material in the IBERS breeding programme and the experimental mapping population, there are also considerable differences. These may result from the different backgrounds of the original plant materials.

To the best of our knowledge, no QTL study in perennial ryegrass has succeeded in explaining the major part of phenotypic variation for a quantitative trait, and the percentage variation explained by individual QTL has been low, although the high heritabilities for many of these traits indicate strong genetic control. For plant morphology/productivity traits, the percentage variation explained has only rarely been greater than $20 \%$ [24-27]. The same is true for plant quality traits including WSC content $[1,23]$. In conjunction with this, 
marker selection has confirmed individual QTL locations but failed to realise substantial gains in WSC content [28]. Test crosses based on marker indices have been only slightly more successful [29, and Turner, unpublished data]. This is all consistent with polygenic control from multiple loci spread across the genome. Future strategies for marker selection of key traits that may be difficult or expensive to assess in forage grasses will therefore need to be based on genome-wide approaches [20].

In conclusion, the strategy followed here of creating an initial population and selecting phenotypically for a given trait during a number of generations has been further confirmed to produce divergence. It has also facilitated the identification of more QTLs for polygenic traits than previously found in single cross mapping populations. Provided that a range of suitable genetic variation is present, the selection intensity is sufficiently strong and the genotyping sufficiently dense; this shows that this approach can complement QTL mapping studies based on bi-parental populations.

Acknowledgments We thank Miss JE Ashton for running the HPLC analyses. This work was funded by the European Union (EU) Framework IV GRASP project QLK5-CT-2002-00862, Defra LS 3649, Biotechnology and Biological Research Council (BBSRC) grant numbers ISPG 03134 CFC, ISPG 10963A, and BBS/E/W/10963A01, and Integrated Biorefining Research and Technology Club (IBTI Club) BB/I005390/1 plus ERDF/WEFO (BEACON).

Open Access This article is distributed under the terms of the Creative Commons Attribution License which permits any use, distribution, and reproduction in any medium, provided the original author(s) and the source are credited.

\section{References}

1. Turner LB, Cairns AJ, Armstead IP, Ashton J, Skøt K, Whittaker D, Humphreys MO (2006) Dissecting the regulation of fructan metabolism in perennial ryegrass (Lolium perenne) with quantitative trait locus mapping. New Phytol 169:45-58

2. Humphreys MO (1989) Water-soluble carbohydrates in perennial ryegrass breeding. II. Cultivar and hybrid progeny performance in cut plots. Grass Forage Sci 44:237-244

3. Wilkins PW, Humphreys MO (2003) Progress in breeding forage grasses for temperate agriculture. J Agric Sci 140:129-150

4. Gallagher JA, Turner L, Cairns AJ (2007) Fructan in temperate forage grasses; Agronomy, physiology and molecular biology.In: Shiomi N, Benkeblia N, Onodera S, eds. Recent Advances in Fructoologosaccharides Research, Kerala, India: Research Signpost, pp15-46

5. Warwel S, Bruse F, Demes C, Kunz M, Klaas MR (2001) Polymers and surfactants on the basis of renewable resources. Chemosphere 43:39-48

6. Vieira de Almeida M, Le Hyaric M (2005) Carbohydrate-derived surfactants. Mini-Rev Org Chem 2:283-297

7. Farrar K, Bryant DN, Turner L, Gallagher J, Thomas A, Farrell M, Humphreys MO, Donnison IS (2012) Breeding for bioethanol production in Lolium perenne L.: Association of allelic variation with high water-soluble carbohydrate content. Bioenergy Res 5:149-157
8. Turner LB, Skot K, Farrell M, Cairns AJ, Armstead IP, Farrar K, Donnison IS, Humphreys MO (2009) Changes in SSR allele frequencies during phenotypic selection for water-soluble carbohydrate (WSC) in an experimental population of perennial ryegrass. In: Lübberstedt, T. et al. (ed) Proceedings, 27th EUCARPIA Symposium on Improvement of Fodder Crops and Amenity Grasses, Copenhagen, 19-23 August 2007. p. 27

9. Humphreys MO (1989) Water-soluble carbohydrates in perennial ryegrass breeding. I. Genetic differences among cultivars and hybrid progeny grown as spaced plants. Grass Forage Sci 44:231-236

10. Posselt UK, Barre P, Brazauskas G, Turner LB (2006) Comparative analysis of genetic similarity between perennial ryegrass genotypes investigated with AFLPs, ISSRs, RAPDs and SSRs. Czech J Genet Plant Breed 42:87-94

11. Payne RW, Harding SA, Murray DM, Soutar DM, Baird DB, Glaser AI, Channing IC, Welham SJ, Gilmour AR, Thompson R, Webster R (2010) GenStat ${ }^{\mathbb{R}}$ for Windows ${ }^{\circledR}$ 13th Edition, Introduction. VSN International, Hemel Hempstead

12. Gill GP, Wilcox PL, Whittaker DJ, Winz RA, Bickerstaff P, Echt CE, Kent J, Humphreys MO, Elborough KM, Gardner RC (2006) A framework linkage map of perennial ryegrass based on SSR markers. Genome 49:354-364

13. Goudet, J (2001) FSTAT, a program to estimate and test gene diversities and fixation indices (version 2.9.3). http://www2.unil.ch/ popgen/softwares/fstat.htm.

14. Raymond M, Rousset F (1995) GENEPOP (version 1.2): population genetics software for exact tests and ecumenicism. J Hered 86:248-249

15. Rousset F (2008) Genepop'007: a complete reimplementation of the Genepop software for Windows and Linux. Mol Ecol Resour 8:103-106

16. Beaumont MA, Nichols RA (1996) Evaluating loci for use in the genetic analysis of population structure. Proc R Soc Lond B 263: $1619-1626$

17. Antao T, Lopes A, Lopes RJ, Beja-Pereira A, Luikart G (2008) LOSITAN: a workbench to detect molecular adaptation based on a $\mathrm{F}_{\mathrm{ST}}$-outlier method. BMC Bioinformatics 9:323

18. Fu Y-B, Somers DJ (2011) Allelic changes in bread wheat cultivars were associated with long-term wheat trait improvements. Euphytica 179:209-225

19. Falke KC, Flachenecker AE, Melchinger AE, Piepho H-P, Maurer HP, Frisch M (2007) Temporal changes in allele frequencies in two European F2 flint maize populations under modified recurrent fullsib selection. Theor Appl Genet 114:765-776

20. Hayes BJ, Cogan NOI, Pembleton LW, Goddard ME, Wang J, Spangenberg GC, Forster JW (2013) Prospects for genomic selection in forage plant species. Plant Breed 132:133-143

21. Auzanneau J, Huyghe C, Julier B, Barre P (2007) Linkage disequilibrium in synthetic varieties of perennial ryegrass. Theor Appl Genet 115:837-847

22. Brazauskas G, Lenk I, Pedersen MG, Studer B, Lubberstedt T (2011) Genetic variation, population structure and linkage disequilibrium in European elite germplasm of perennial ryegrass. Plant Sci 181:412420

23. Cogan NOI, Smith KF, Yamada T, Francki MG, Vecchies AC, Jones ES, Spangenberg GC, Forster JW (2005) QTL analysis and comparative genomics of herbage quality traits in perennial ryegrass (Lolium perenne L.). Theor Appl Genet 110:364-380

24. Yamada T, Jones ES, Cogan NOI, Vecchies AC, Nomura T, Hisano H, Shimamoto Y, Smith KF, Hayward MD, Forster JW (2004) QTL analysis of morphological, developmental, and winter hardiness-associated traits in perennial ryegrass. Crop Sci 44:925-993

25. Sartie AM, Matthew C, Easton HS, Faville MJ (2011) Phenotypic and QTL analyses of herbage production-related traits in perennial ryegrass (Lolium perenne L.). Euphytica 182(315):315-315 
26. Kobayashi S, Humphreys MO, Tase K, Sanada Y, Yamada T (2011) Molecular marker dissection of ryegrass plant development and its response to growth environments and foliage cuts. Crop Sci 51:600-611

27. Khaembah EN, Irving LJ, Thom ER, Faville MJ, Easton HS, Matthew C (2013) Leaf Rubisco turnover in a perennial ryegrass (Lolium perenne L.) mapping population: genetic variation, identification of associated QTL, and correlation with plant morphology and yield. J Exp Bot 64:1305-1316
28. Turner LB, Farrell M, Humphreys MO, Dolstra O (2010) Testing watersoluble carbohydrate QTL effects in perennial ryegrass (Lolium perenne L.) by marker selection. Theor Appl Genet 121:1405-1417

29. Dolstra O, Denneboom C, de Vos ALF, van Loo EN (2007) Markerassisted selection for improving quantitative traits of forage crops. In: Guimarães EP, Ruane J, Scherf BD, Sonnino A, Dargie JD (eds) Marker-assisted selection: current status and future perspectives in crops, livestock, forestry and fish. FAO, Rome, pp 59-65 